\title{
Effect of Prolonged Beta-Adrenergic Blockade Induced by Atenolol on Left Ventricular Remodeling after Acute Myocardial Infarction in the Rat
}

\author{
Ken-ei Shimada, M.D., Toshio Nishikimi, M.D.,* \\ Takahiko Kawarabayashi, M.D., Kazuhide Takeuchi, M.D., \\ and Tadanao TAKedA, M.D.
}

\section{SUMMARY}

Beta-adrenergic receptor blockade reduces the mortality rate after acute myocardial infarction (AMI) in humans. However, the effects of beta blockade on left ventricular remodeling remain unknown. Therefore, in the present study we investigated the effect of prolonged beta-adrenergic receptor blockade with atenolol on left ventricular remodeling following AMI in rats. Myocardial infarction (MI) was produced in Wistar-Kyoto rats by ligating the coronary artery. Four groups of rats were studied: sham-operated $(n=10)$; atenolol ( $1 \mathrm{~g}$ / $l$ in drinking water) treated sham-operated $(n=8)$; untreated MI $(n=11)$; atenolol treated MI $(n=10)$. Hemodynamic measurements were made about 3 weeks after the operation. Infarct size was similar in treated and untreated MI rats $(31.2 \pm 2.5 \%$ cf. $33.5 \pm 2.0 \%)$. MI rats were characterized by increases in left ventricular end-diastolic pressure (LVEDP), right atrial pressure (RAP), right ventricular systolic pressure (RVSP), and left ventricular end-diastolic volume index (LVEDVI), as compared with sham-operated rats. In sham-operated rats, prolonged beta-adrenergic receptor blockade produced only a reduced HR. Atenolol-treated MI rats had a significantly higher LVEDP, RAP and LVEDVI than did rats with untreated MI. Prolonged beta-adrenergic receptor blockade with atenolol appeared to promote left ventricular remodeling after AMI. Thus, the treatment of AMI with beta-adrenergic receptor blockade in the clinical setting should be evaluated with respect to ventricular remodeling during prolonged therapy. (Jpn Heart J 36: 81-89, 1995)

Key words: myocardial infarction beta-adrenergic blockade left ventricular remodeling

$7 \mathrm{HE}$ administration of a beta-adrenergic receptor blocker reduces mortality after Q-wave acute myocardial infarction (AMI) in humans. Yusuf et al reported that, among 50,000 patients randomized in multiple multicenter trials

\footnotetext{
From First Department of Internal Medicine, Osaka City University Medical School, Osaka, and * Division of Hypertension and Kidney Disease, National Cardiovascular Center, Osaka, Japan.

Address for correspondence: Toshio Nishikimi, M.D., Division of Hypertension and Kidney Disease, National Cardiovascular Center, 5-7 1, Fujishirodai, Suita, Osaka 565, Japan.

Received for publication August 18, 1994.

Accepted October 5, 1994.
} 
to beta-adrenergic receptor blockade and placebo, the treated group showed $25 \%$ reduction in mortality. "The first International Society of Infarct Survival-1 trial demonstrated an additional decrease in short-term mortality when the selective beta-antagonist, atenolol, was administered within 7 days after AMI. The greatest decrease in mortality was observed when the drug was administered within the first 24 to $48 \mathrm{~h}$ after the event. ${ }^{2)}$ Although it has the potential to produce beneficial effects after AMI, beta-adrenergic receptor blockade can also precipitate or exacerbate congestive heart failure, particularly in a patient with a large transmural MI. A large MI can alter the topography of both the infarcted and non-infarcted regions of the ventricle. This remodeling may affect the function of the ventricle and influence the prognosis. The present study investigated the effect of prolonged beta-adrenergic receptor blockade with atenolol on left ventricular remodeling after $\mathrm{AMI}$ in rats.

\section{Methods}

Experimental infarction: Male Wistar-Kyoto (WKY) rats (Kcary Japan Inc., Osaka, Japan) (250-330 g) were kept at a controlled room temperature of $22^{\circ} \mathrm{C}$ under a 12-h: 12-h light-dark cycle, provided with regular pelleted rat chow and given water ad libitum. The study protocol was approved by the Osaka City University Animal Care and Use Committee. After an acclimatization period of at least 3 days, myocardial infarction was produced in these rats by techniques similar to those described previously. ${ }^{3-5)}$ In brief, after inducing anesthesia with pentobarbital ( $30 \mathrm{mg} / \mathrm{kg}$ i.p.), the animals were intubated and subjected to positive-pressure ventilation. The left chest was then opened in the fourth intercostal space. The pericardium was incised and opened, and a 60 prolene suture was placed around the left main coronary artery as a ligature. The chest was then closed with a $3-0$ silk suture.

Protocol: The total of twenty-one MI and eighteen sham-operated rats were divided randomly into four groups: untreated MI $(n=11)$, atenolol treated MI $\langle n=10)$, untreated sham $(n=10)$, and atenolol treated sham $(n=8)$. The treatment (atenolol, $1 \mathrm{~g} / l$ in drinking water) was begun the day after the operation.

A preliminary study was conducted to determine the effective dose of atenolol. Sincc the water intake of the rats was about $30 \mathrm{ml}$ a day, the atenolol intake was approximately $100 \mathrm{mg} / \mathrm{kg} /$ day. An infusion of isoproterenol, $0.1 \mu \mathrm{g} /$ $\mathrm{kg} / \mathrm{min}$, increased the HR from $364 \pm 22$ to $512 \pm 63(41 \%)$ in untreated anesthetized rats $(n=4)$. By contrast, the $\beta$-adrenoceptor-mediated increase of HR was clearly inhibited in the atenolol-trcated rats $(1 \mathrm{~g} / l$ in drinking water $)(n=4)$, increasing from $348 \pm 22$ to $391 \pm 55(12 \%, p<0.01)$. Thus, atenolol administration by $1 \mathrm{~g} / \mathrm{l}$ in drinking water was considered to sufficiently block the beta- 
adrenoceptor in rats.

Hemodynamic studies: Hemodynamic measurements were made about 3 weeks after the operation. Rats were anesthetized with pentobarbital $130 \mathrm{mg} / \mathrm{kg}$ i.p) and the right carotid artery and right external jugular vein were cannulated with polyethylene ( $\mathrm{PE})$ tubing, $(0.58 \mathrm{~mm}$ inside diameter) connected to a solidstate pressure transducer (Model P23 ID, Gould Inc., California, USA). Body temperature was maintained between $36-38^{\circ} \mathrm{C}$ with a heating table, while the rat breathed spontaneously. Left ventricular, systemic arterial, right atrial and right ventricular pressures were recorded and the mean values were determined by electronic averaging on a physiological recorder (RF-85, Fukuda Denshi, Tokyo, Japan). Left ventricular end-diastolic pressure and $\Delta \mathrm{dp} / \mathrm{dt}$ were also measured. Heart rate was determined from the arterial pressure tracing.

Pressure-volume relationship: Pressure-volume data were recorded by the methods described previously. ${ }^{6}$ After completing the hemodynamic studies, we injected $1.0 \mathrm{~m} l$ of $2 \mathrm{mM} \mathrm{KCl}$ via the jugular venous catheter to arrest the heart in diastole. The heart was quickly excised and the right ventricle was incised. Two PE-50 catheters, attached to a solid-state pressure transducer and an infusion pump (Model STC-325, Terumo, Tokyo, Japan), were passed into the left ventricle. The atrioventricular groove was identified and a ligature was passed around the heart and tied, isolating the left atrium from the left ventricle. After gently aspirating the left ventricular cavity to remove any residual blood and to reduce the pressure to $-5 \mathrm{mmHg}$, we infused normal saline at $0.68 \mathrm{ml} / \mathrm{min}$ into the suspended left ventricle and simultaneously recorded the pressure. Saline was infused until the pressure rose to $30 \mathrm{mmHg}$ and the infusion was stopped. Three curves were obtained from each left ventricle within 15 min of cardiac arrest. Left ventricular volume was determined from the isolated left ventricular pressurevolume relationship at end-diastolic pressure. After the pressure-volume curve measurements had been obtained, the right and left ventricles (including the interventricular septum) were dissected free, separated, and weighed.

Infarct size determination: The heart was dissected free of adjacent tissues and the left ventricle was opened via an incision of the septum from base to apex. Both ventricles were weighed immediately. Myocardial infarct size was measured by the techniques described previously. ${ }^{7}$ Briefly, incisions were made in the left ventricle so that the left ventricular tissue could be pressed flat. The circumferences of the left ventricle and the region of infarction were outlined on clear semitransparent paper for both the endocardial and epicardial surfaces. Infarct size was calculated and expressed as a percentage of left ventricular surface area based on the weight of the areas marked on the semitransparent paper.

Statistical analysis: All results are presented as mean \pm SEM. Statistical comparisons between groups were made using one-way analysis of variance. A level 
of $p<0.05$ was accepted as statistically significant.

\section{Results}

Baseline measurements: Body weight did not differ significantly among the four test groups (Table I). While the left ventricular weight/body weight tended to be higher by $16 \%$ in atenolol treated rats with myocardial infarction as compared with untreated rats with myocardial infarction, the difference was not statistically significant. Right ventricular weight/body weight was increased by the induction of myocardial infarction, but was unchanged in the sham-operated rats treated with atenolol.

However, the infarct size, measured 3-weeks after the operation, did not differ significantly between the atenolol-treated and untreated $\mathrm{MI}$ groups $(31.2 \% \pm 2.5$ cf. $33.5 \% \pm 2.0$, N.S.).

Hemodynamic measurements: Hemodynamic values appear in Table II. Heart rate was decreased by both the myocardial infarction and the administration of atenolol. Mean arterial pressure was decreased by the myocardial infarction, but was not altered in sham-operated rats given atenolol treatment.

Table I. Body Weight and Heart Weights in Untreated and Atenolol-treated Rats

\begin{tabular}{lccccc}
\hline & Sham & Atenolol-treated sham & & Untreated MI & Atenolol-treated MI \\
\cline { 2 - 3 } \cline { 5 - 6 }$n$ & 10 & 8 & 11 & 10 \\
$\mathrm{BW}(\mathrm{g})$ & $289 \pm 32$ & $290 \pm 28$ & & $314 \pm 8$ & $301 \pm 5$ \\
$\mathrm{LVW}(\mathrm{mg} / \mathrm{g} \mathrm{BW})$ & $2.02 \pm 0.04$ & $1.99 \pm 0.03$ & & $1.94 \pm 0.17$ & $2.25 \pm 0.06$ \\
$\mathrm{RVW}(\mathrm{mg} / \mathrm{g} \mathrm{BW})$ & $0.55 \pm 0.22$ & $0.54 \pm 0.11$ & & $0.85 \pm 0.55^{++}$ & $1.03 \pm 0.88^{++}$ \\
\hline
\end{tabular}

Values are mean \pm SEM. $\mathrm{BW}=$ body weight; $\mathrm{LVW}=$ left ventricular weight; $\mathrm{RVW}=$ right ventricular weight; $p<0.05{ }^{++} p<0.01$ vs sham.

Table II. Infarct Size, Heart Rate, LV Pressure, LV $\Delta \mathrm{dP} / \mathrm{dt}$, Right Atrial Pressure, and Right Ventricular Pressure in Untreated and Atenolol-treated Rats

\begin{tabular}{lcccc}
\hline & Sham & Atenolol-treated sham & Untreated MI & Atenolol-treated MI \\
\hline$n$ & 10 & 8 & 11 & 10 \\
Infarct size $(\%)$ & & $33.5 \pm 2.0$ & $31.2 \pm 2.5$ \\
Heart rate $(\mathrm{beats} / \mathrm{min})$ & $371 \pm 15$ & $303 \pm 5^{++}$ & $323 \pm 10^{+}$ & $277 \pm 6^{+* * *}$ \\
MAP $(\mathrm{mmHg})$ & $113 \pm 5$ & $104 \pm 3$ & $98 \pm 5^{+}$ & $91 \pm 5^{+}$ \\
LVEDP $(\mathrm{mmHg})$ & $3.5 \pm 0.3$ & $3.9 \pm 0.6$ & $7.5 \pm 1.5^{+}$ & $13.0 \pm 1.9^{+* * *}$ \\
LV $\Delta \mathrm{dP} / \mathrm{dt}(\mathrm{mmHg})$ & $7,410 \pm 536$ & $5,152 \pm 193^{++}$ & $6,155 \pm 297^{+}$ & $5,573 \pm 191^{++}$ \\
RAP $(\mathrm{mmHg})$ & $1.6 \pm 0.3$ & $1.2 \pm 0.2$ & $2.5 \pm 0.3$ & $3.5 \pm 0.5^{+*}$ \\
RV Sys $\mathrm{P}(\mathrm{mmHg})$ & $31 \pm 2$ & $28 \pm 2$ & $40 \pm 3^{+}$ & $44 \pm 2^{+}$ \\
\hline
\end{tabular}

Values are mean \pm SEM. MAP = mean arterial pressure; $L V=$ left ventricular; EDP, end diastolic pressure; $\mathrm{RAP}=$ right atrial pressure; $\mathrm{RV}$ Sys $\mathrm{P}=$ right ventricular systolic pressure; ${ }^{+} p<0.05 \quad+p<0.01 \mathrm{cf}$. Sham, $* p<0.05 * * 0<0.01$ vs Untreated MI. 


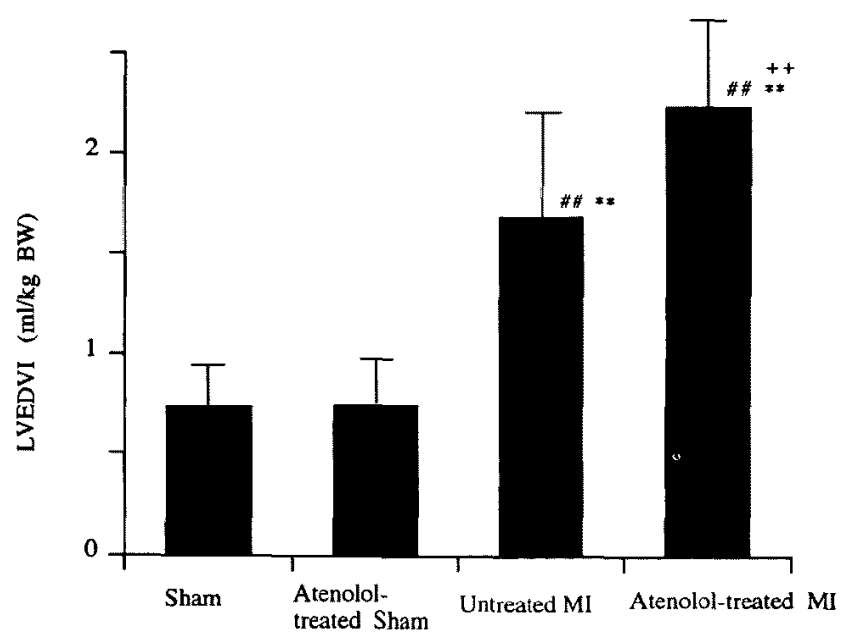

Figure 1. Left ventricular end diastolic volume index (LVEDVI) in sham untreated and atenolol-treated MI rats. ${ }^{* *} p<0.01$ vs Sham ${ }^{* *} p<0.01$ vs Atenolol treated sham, ${ }^{+4} p<0.01$ vs Untreated MI.

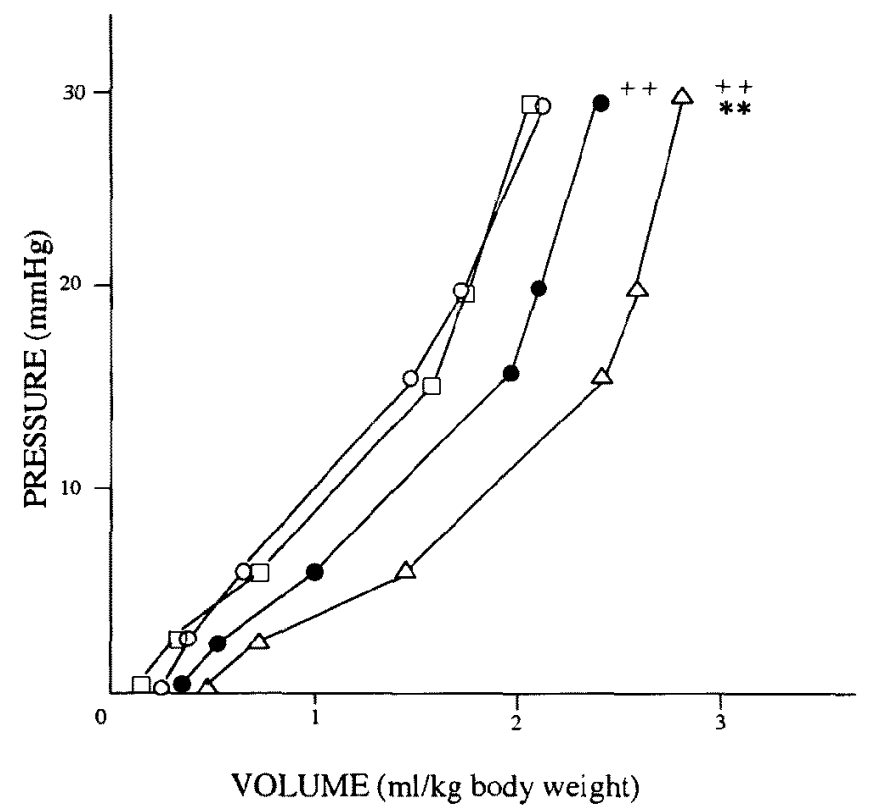

Figure 2. Left ventricular pressure-volume relationships in the four groups of rats.

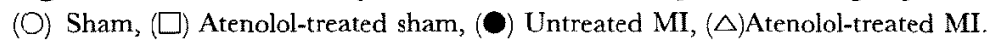
${ }^{++} p<0.01$ vs Sham, ${ }^{* *} p<0.01$ vs Untreated MI.

The increase in left ventricular end-diastolic pressure after myocardial infarction was exacerbated by atenolol treatment and the left ventricular $\Delta \mathrm{dp} / \mathrm{dt}$ was decreased in rats with myocardial infarction and in sham-operated rats treated with 
atenolol. The right atrial pressure increased significantly only in the rats with myocardial infarction that were treated with atenolol. The left ventricular enddiastolic volume index was increased in both the untreated and atenolol-treated rats with MI (Figure 1).

Left ventricular pressure-volume relations: The left ventricular pressurevolume relationships between the four groups of rats are shown in Figure 2. The induction of myocardial infarction shifted the relationship to the right such that, at any given pressure, the left ventricular volume was elevated. The pressurevolume relationship in the rats with MI treated with atenolol was shifted farther to the right as compared with the untreated rats with MI. This was statistically significant (by ANOVA, $p<0.01$ ).

\section{Discussion}

This study has demonstrated that prolonged beta-adrenergic receptor blockade increased the right atrial pressure, the left ventricular end-diastolic pressure, and the left ventricular end-diastolic volume index in rats with myocardial infarction that was induced by ligating the coronary artery. The degree of LV dilatation after AMI is an important determinant of prognosis following AMI. ${ }^{7-17)}$ The fact that prolonged treatment with a beta-adrenergic receptor blocker after AMI accelerated the $\mathrm{LV}$ remodeling in rats may suggest that attention should be paid to such treatment in patients with MI.

Maroko et $\mathrm{al}^{18)}$ reported that the intravenous administration of propranolol inhibits ST elevation in the electrocardiogram and reduces infarct size in dogs $3 \mathrm{~h}$ after coronary artery ligation. The release of catecholamines is increased in MI, suggesting that the sympathetic nervous system and a compensatory neurohumoral mechanism are activated in the course of the cardiac dysfunction caused by MI. Although catecholamines increase the heart rate, cardiac contractility, and the blood pressure, such agents also increase cardiac consumption of oxygen. Catecholamines can also directly accelerate the cardiac injury and increase the size of the infarct. Beta-adrenergic receptor blockade may have the following favorable pharmacological effects in MI: (a) a negative chronotropic and inotropic effect; (b) a reduction of the oxygen consumption of the ischemic myocardium, and (c) an antiarrhythmic effect. These effects would improve the prognosis of patients with MI.

Two large clinical epidemiologic studies have shown that the administration of a beta-adrenergic receptor blocker soon after MI reduced both the morbidity and mortality of this disorder. ${ }^{2.19)}$ Chronic beta-adrenergic receptor blockade is also rcported to inhibit reinfarction and arrhythmia, and to reduce the incidence of sudden death. The combined pharmacological effects noted above may help to 
reduce the mortality following MI.

During chronic heart failure, the myocardium is exposed to a chronic activation of the sympathetic nervous system and the number of beta-adrenoceptors in cell membranes of myocardial cells is decreased by down regulation. ${ }^{20)}$ Aarons et $\mathrm{al}^{21)}$ reported that the number of beta-adrenoceptors in these cell membranes increases after treating rats with chronic heart failure with a beta-adrenergic receptor blocker. In AMI, the contraction of the non-infarcted myocardium is increased by the Frank-Starling mechanism to maintain cardiac function, termed the cardiac reserve. It has recently been reported that a transformation of myosin isoforms occurs during myocardial infarction in rats.

Since LV remodeling can lead to cardiac thrombosis, heart failure, and cardiac arrhythmia, it may result in a poor prognosis. Hochman and Wong ${ }^{22)}$ reported that the administration of atenolol did not inhibit MI expansion in the rat 1 week after AMI; they administered atenolol for only 7 days, and compared $\mathrm{LV}$ volume with that in untreated $\mathrm{MI}$ rats. Gay et $\mathrm{al}^{23)}$ reported that chronic propranolol administration did not inhibit LV remodeling after $\mathrm{MI}$ in the rat, and also showed that propranolol increased the LVEDP and RAP without changing cardiac output. Although their protocols were different from ours, our hemodynamic results seem to be consistent with those previously reported. Betaadrenergic receptor blockade increased the preload, such as LVEDP and RAP, by its negative inotropic and chronotropic effects. An increase in preload leads to an increase in wall stress, an important stimulus to the development of cardiac hypertrophy. Preload is also increased in cardiac dysfunction due to myocardial infarction. Therefore, treatment of myocardial infarction and heart failure with a $\beta$-adrenergic receptor blocker may further increase the preload and produce LV remodeling.

We showed that prolonged beta-adrenergic receptor blockade after AMI accelerated dilatation of the LV and worsened hemodynamics in the rat. However, clinical epidemiological studies have demonstrated a favorable effect of beta-adrenergic receptor blockade on the morbidity and mortality of patients with ischemic heart disease.

Thus, the clinical results seem to differ from our experimental findings. Several factor may explain in this discrepancy. First, our study produced MI by ligating the coronary artery in relatively young rats. The etiology of MI in rats differes from that in humans. The latter is due to atherosclerosis occurring in all coronary arteries, which produces myocardial ischemia. Beta-adrenergic receptor blockade may be effective at treating such atherosclerosis-based ischemia in humans. Second, we assessed hemodynamics and LV dilatation 3-4 weeks after the onset of MI in rats. The healing of an MI lesion reportedly requires at least 3 weeks. The 3 to 4 week period used in this study is long enough for an examina- 
tion of the LV remodeling process after AMI, but may be too short to assess the effect of long-term beta-adrenergic receptor blockade. Hence, our results have limited clinical applicability. Nevertheless, the MI model used in the present study is similar to the large MI that occur in relatively younger people. In such patients, the MI is usually caused by thrombosis and coronary artery spasm. In these cases, the chronic administration of beta-adrenergic receptor blocker after MI may accelerates LV remodeling and merits clinical consideration.

\section{REFERENCES}

1. Yusuf S, Peto R, Lewis J, Collins R, Sleight P: Beta blockade during and after myocardial infarction; an overview of the randomized trials. Prog Cardiovasc Dis 27: 335, 1985

2. ISIS-1 Collaborative Group: A randomized trial of intravenous atenolol among 16,027 cases of suspected acute myocardial infarction. Lancet 2: 57, 1986

3. Selye H, Bajusz E, Grasso S, Mendell P: Simple techniques for the surgical occlusion of coronary vessels in the rat. Angiology 11: 398, 1960

4. Johns TNP, Olson BJ: Experimental myocardial infarction. I: A method of coronary occlusion in small animals. Ann Surg 140: 675, 1954

5. Nishikimi $T$, Uchino $K$, Frohlich EP: Effect of $\alpha 1$-adrenergic blockade on intrarenal hemodynamics in heart failure rats. Am J Physiol 262 (Regulatory Integrative Com. Physiol. 31): R198, 1992

6. Fletcher PJ, Pfeffer MA, Pfeffer JM, Braunwald E: Left ventricular diastolic pressure-volume relations in rats with healed myocardial infarction; effects on systolic function. Circ Res 49: 618, 1981

7. Chien YW, Barbee RW, Macphee AA, Frohlich ED, Trippodo NC: Increased ANF secretion after volume expansion is preserved in rats with heart failure. Am J Physiol 23: R185, 1988

8. Pfeffer MA, Braunwald E, Moye LA, Basta L, Brown EJ Jr, Cuddy TE, Davis BR, Geltman EM, Goldman S, Flaker GC: Effect of captopril on mortality and morbidity in patients with left ventricular dysfunction after myocardial infarction. N Engl J Med 327: 669, 1992

9. Bonaduce D, Petretta M, Villari B, Breglio R, Conforti G, Montemurro MV, Lonzillo T, Morgano G: Effects of late administration of tissue-type plasminogen activator on left ventricular remodeling and function after myocardial infarction. J Am Coll Cardiol 16: 1561, 1990

10. Marino P, Zonolla L, Zardini P: Effect of streptokinase on left ventricular remodeling and function after myocardial infarction; the GISSI Trial. J Am Coll Cardiol 14: 1149, 1989

11. Topol EJ, Califf RM, Vandormael M, Grines CL, George BS, Sanz ML, Wall T, O'Brien M, Schwaiger M, Aguirre FV: A randomized trial of late reperfusion therapy for acute myocardial infarction. Circulation 85: 2090, 1992

12. Hochman JS, Choo H: Limitation of myocardial infarct expansion by reperfusion independent of myocardial salvage. Circulation 75: 2999, 1987

13. Pfeffer MA, Braunwald E: Ventricular remodeling after myocardial infarction; experimental observations and clinical implications. Circulation 81: 1161, 1990

14. Kostuk WJ, Kazamias TM, Gander MP, Simon AL, Ross J Jr: Left ventricular size after acute myocardial infarction; serial changes and their prognostic significance. Circulation 47: 1174, 1973

15. Braunwald E: Myocardial reperfusion, limitation of infarct size, reduction of left ventricular dysfunction, and improved survival; should the paradigm be expanded? Circulation 79: 441, 1989

16. Mckay RG, Pfeffer MA, Pasternak RC, Markis JE, Come PC, Nakao S, Alderman JD, Ferguson JI, Safian RD, Grossman W: Left ventricular remodeling after myocardial infarction; a corollary to infarct expansion. Circulation 74: 693, 1986

17. Olivetti G, Capasso JM, Meggs LG, Sonnenblick EH, Anversa P: Celluar basis of chronic ventricular remodeling after myocardial infarction in rats. Circ Res 68: 856, 1991

18. Maroko PR, Kjekshus JK, Sobel BE, Watanabe T, Covell JW, Ross J Jr, Braunwald E: Factors influencing infarct size following experimental coronary artery occlusion in dogs. Circulation 43: 67 , 
1971

19. The MIAMI Trial Research Group: Metoprolol in acute myocardial infarction (MIAMI); a randomized placebo-controlled international trial. Eur Heart J 6: 199, 1985

20. Bristow MR, Ginburg R, Minobe W, Cubicciotti RS, Sageman WS, Lurie K, Billingham ME, Harrison $\mathrm{DC}$, Stinson $\mathrm{EB}$ : Decreased catecholamine sensitivity and $\beta$-adrenergic receptor density in failing human hearts. New Engl J Med 307: 205, 1982

21. Aarons RD, Nies AS, Gerber JG, Molinoff PB: Decreased beta adrenergic receptor density on human lymphocytes after chronic treatment with agonist. J Pharmacol Exp Ther 224: 1, 1983

22. Hochman JS, Wong SC: Effect of atenolol on myocardial infarct expansion in a non-reperfused rat model. Am Heart J 122: 689, 1991

23. Gay RG, Raya TE, Goldman S: Chronic propranolol treatment promotes left ventricular dilatation without altering systolic function after large myocardial infarction in rats. J Cardiovasc Pharmacol 16: 529, 1990 